\title{
Methods on Parathyroid Protection in Thyroid Surgery, Present and Future
}

\author{
Liu J* and Zheng M \\ Department of Breast-thyroid Surgery, China
}

Submission: May 06, 2017; Published: July 06, 2017

*Corresponding author: Liu J, Department of Breast-thyroid Surgery, Shanghai General Hospital, 201620, Shanghai, China, Email: liujun95039@163.com

\section{Introduction}

Thyroid surgery is a widely performed operation in recent two decades with complication rate less than 5\% [1]. Parathyroid damage is most frequent complication of thyroid surgery because parathyroid is near to or even inside of thyroid gland, and because it is a challenge to distinguish by naked eyes. It has been reported that the incidental rate of parathyroidectomy in thyroid surgery ranges between $6.4 \sim 31 \%$ [2]. Incidental parathyroidectomy can cause mild to serious hypocalcemia which in turn impair quality of patient's life. So it is important to protect parathyroid and to keep its' normal function in thyroid surgery. There are several methods, which identify and protect the parathyroid glands in thyroid surgery, have been developed in the past several years and have being developed in recent years.

\section{Methods in the Present}

One parathyroid principle. This means to treat any parathyroid as the last one. One reason is that the number of parathyroid glands varies from 2 to more than 4 [3]. The second reason is that it is not ensure not to damage other parathyroid glands. So all of the parathyroid glands identification is needed as possible as we can in the thyroid surgery. And meticulous dissection should be done to reserve the parathyroid glands and the main blood supply to them. The second meaning of one parathyroid principle is one parathyroid gland should be identified when thyroid surgery has been done to ensure not developing to permanent hypocalcemia.

Operation selection. The rate of incidental parathyroidectomy is associated with bilateral total thyroidectomy, central lymph node dissection [4] and experience of the surgeon. So if the lobectomy is enough, do not do the bilateral total thyroidectomy. The lower the experience of the surgeon has, the smaller the operation range should be done to reduce the rate of complications. As the better prognosis of thyroid cancer, the parathyroid glands damage should be well balanced with the recurrence of the cancer.
Anatomic location. Though the location of the parathyroid glands are varied, there are some common anatomic location clues can be tracked.

I. Relation to recurrent laryngeal nerve [5]. The inferior parathyroid glands are consistently anterior to the recurrent laryngeal nerve, while the superior parathyroid gland is always posterior to the recurrent laryngeal nerve.

II. Relation to thyroid gland. Most parathyroid glands are tightly attached to the dorsal or lateral surface of thyroid lobes, often located in the fiber thyroid capsule between the natural and surgical coatings.

III. The lower corner of the thyroid cartilage [6]. 85\% of the superior parathyroid glands concentrates in the circle with a radius of $1 \mathrm{~cm}$ area with the lower corner of the thyroid cartilage as the center.

IV. Lower $1 / 3$ of the junction of the posterior edge of the thyroid. More than $50 \%$ of the inferior parathyroid glands locates at this junction.

\section{Appearance identification}

The normal parathyroid glands are usually not easily distinguishable from surrounding tissues such as droplets, lymph nodes, and thyroid nodules in thyroid surgery. There are some appearance features which can be helpful to identify parathyroid glands [6].

I. Size and thickness: The average diameter of normal parathyroid glands is $4-6 \mathrm{~mm}$, and the maximum diameter is rarely $>8 \mathrm{~mm}$, while thyroid nodules are often about $10 \mathrm{~mm}$. The thickness of the parathyroid glands is much smaller than their length and width, usually at only $1-2 \mathrm{~mm}$, while the thickness of lymph nodes are more similar with length and width. 
II. Color: Parathyroid glands are brown or yellowish brown or tan, while lymph nodes are pink, fatty droplets are pale yellow.

III. Capsule: Parathyroid glands have a complete capsule with some fatty tissues surrounded, while fatty droplets do not have capsules.

IV. Shape: Parathyroid glands have a smooth and regular shape, while lymph node may have an irregular with an uneven surface.

V. Blood supply: Parathyroid glands are sensitive to blood supply changes. When their arteries are damaged, they become pale quickly, and when their veins are injured, they become purple as congestion. But the fatty droplet, lymph node and some thyroid nodules are not so sensitive to blood supply changes.

VI. Texture: The texture of the parathyroid glands is softer than the lymph node, and harder than the fatty droplet.

With the anatomic location and appearance features, more than half of the parathyroid glands can be identified by the naked eye, while the identification of the rest of them needs additional methods.

\section{Negative development}

Here may be referred to carbon nanoparticles, which diameter is about $150 \mathrm{~nm}$. When carbon nanoparticles have been injected into the thyroid tissue, they will not enter the blood vessel, which the clearance between capillary endothelial cells is $20-50 \mathrm{~nm}$, and they will quickly enter the lymph vessels, which the gap between capillary lymphatic endothelial cells is $120-500 \mathrm{~nm}$. Then the thyroid, lymph node of the drainage area will be dyed black. And the parathyroid glands will be not dyed black. So it makes parathyroid glands readily being distinguished from thyroid and lymph nodes. It is reported that carbon nanoparticles can help to identify parathyroid, especially the inferior parathyroid glands, and reduce the incidental parathyroidectomy in thyroid surgery [7-8]. This expected situation needs well injection technique with appropriate dosage to obtain best result. It cannot perfectly dye all the lymph nodes which we want to remove. It may identify the parathyroid glands only indirectly.

\section{Auto-transplantation}

This is a remedy method to maintain part of the parathyroid function in thyroid surgery [9-10]. When we found that the parathyroid gland has been removed by mistake or the preserved parathyroid gland has bad blood supply, the parathyroid gland involved should be auto-transplanted. So routine examination should be taken on the dissected thyroid and central tissues to identify if parathyroid glands have been removed by mistake before sending them to pathologist. When the tissue removed cannot be identify whether it is parathyroid gland or other tissue, half of it should be sent to intra-operation frozen pathology.
When this half has been identify to be parathyroid gland by frozen section, the rest half should be auto-transplanted. Autotransplantation can be done by particle entrapment into the sternocleidomastoid or by homogenization injection into the forearm muscles. It is reported that auto-transplantation of the parathyroid glands can effectively reduce the rate of severe postoperative permanent hypocalcemia.

\section{Methods in the near Future}

Several studies on how to identify the normal parathyroid intra-operatively have been processed in the recent years. These studies are major in using some devices to detect the auto-fluorescence of the parathyroid or fluorophores within the parathyroid glands.

\section{Auto-fluorescence}

Falco et al. [11] used near infrared light during thyroid and parathyroid surgery, and found that mean parathyroid gland fluorescence intensity (47.60) was significantly higher than the thyroid gland (22.32) and background (9.27) ( $<<0.0001)$. And they found that the use of near infrared light for parathyroid gland visualization significantly increased the number of parathyroid glands identified. McWade et al. $[12,13]$ used near infrared light to detect the auto-fluorescence of the parathyroid and surrounding tissues. They found that parathyroid glands fluorescence was stronger (1.2-18 times) than that of the thyroid with peak fluorescence at $822 \mathrm{~nm}$, and surrounding tissues showed no auto-fluorescence. They also found that the accuracy of this method to detect the parathyroid during thyroid surgery is near $100 \%$, though several factors may affect the signal intensity. Original fluorescent detection apparatus used by Shinden et al. [14] and optical coherence tomography used by Hou et al. [15] showed that they can identify the parathyroid gland during surgery easily and feasible. Auto-fluorescence detected by near infrared light is an indirectly but promising method to identify parathyroid in thyroid surgery.

\section{Fluorophores}

Hyun et al. [16] demonstrated that using near-infrared imaging system to detect the $700 \mathrm{~nm}$ and $800 \mathrm{~nm}$ halogenated fluorophores after intravenous injection can identify the parathyroid and thyroid glands in a high-sensitivity and unambiguous mode in mice and pigs. Suh et al. [17] concluded that indocyanine green NIR fluorescent imaging is useful to identify parathyroid glands during thyroid surgery in dogs. Lavazza et al. [18] reviewed that indocyanine green-enhanced fluorescence for assessing parathyroid perfusion during thyroidectomy, and they concluded that this method merits careful further evaluation for use in thyroid surgery to identify the parathyroid glands by large randomized prospective trials.

Other promising methods.There are several methods might be used in the future to identify parathyroid glands such as intraoperative measurements of intact parathyroid hormone 
through FNA [19], detecting the blood supply of parathyroid glands by laser Doppler flow metryor oxygen spectroscopy.

\section{Conclusion}

There are some matured methods to really helpful to identify and protect parathyroid glands in some degree in present, so we need to practice these methods in thyroid surgery to minimize the parathyroid injury. Some promising researches on how to further identify the parathyroid glands have been processing. The ideal methods may be

1. Applying some drugs to make the parathyroid being easily identified by naked eye without additional device, or

2. Using a device which can tell us the pathologic diagnosis of parathyroid in stainless,real time mode.

We are looking forward to clinical application of these advance techniques to further prevent patients from parathyroid damage in thyroid surgery.

\section{References}

1. Sun GH, DeMonner MM (2013) Epidemiological and economic trends in impatient and outpatient thyroidectomy in the United States, 19962006. Thyroid 23(6): 727-733.

2. Ozoğul B, Akcay MN, Kısaoğlu A, Sabri Selçuk A, Gürkan Ö, et al. (2014) Incidental parathyroidectomy during thyroid surgery: risk factors, incidence, and outcomes. Turk J Med Sci 44: 84-88.

3. Fancy T, Gallagher D, Hornig JD (2010) Surgical anatomy of the thyroid and parathyroid glands. Otolaryngol Clin North Am 43(2): 221-227.

4. Ozemir IA, Buldanli MZ, Yener O, Leblebici M, Eren T, et al. (2016) Factors affecting postoperative hypocalcemia after thyroid surgery: Importance of incidental parathyroidectomy. North Clin Istanbul 3(1): 9-14.

5. Kraas J, Clark PB, Perrier ND, Morton KA (2005) The scintigraphic appearance of subcapsular parathyroid adenomas. Clin Nucl Med 30(4): 213-217.

6. Zhu J, Tian W, Xu Z, Jiang K, Sun H, et al. (2015) Expert consensus statement on parathyroid protection in thyroidectomy. Ann Transl Med 3(16): 230.

7. Wang L, Yang D, Lv JY, Yu D, Xin SJ (2017) Application of carbon nanoparticles in lymph node dissection and parathyroid protection during thyroid cancer surgeries: a systematic review and metaanalysis. Onco Targets therapy 10: 1247-1260.

8. Gao B, Tian W, Jiang Y, Zhang S, Guo L, et al. (2015) Application of carbon nanoparticles for parathyroid protection in reoperation of thyroid diseases. Inter J Clin Exper Med 8(12): 22254-22261.

9. Cui Q Li Z, Kong D, Wang K, Wu G (2016) A prospective cohort study of novel functional types of parathyroid glands in thyroidectomy: In situ preservation or auto-transplantation? Medicine (Baltimore) 95(52): e5810.

10. Anamaterou C, Lang M, Schimmack S, Rudofsky G, Büchler MW, et al. (2015) Autotransplantation of parathyroid grafts into the tibialis anterior muscle after parathyroidectomy: a novel autotransplantation site. BMC Surgery 15: 113.

11. Falco J, Dip F, Quadri P, de la Fuente M, Prunello M, et al. (2017) Increased identification of parathyroid glands using near infrared light during thyroid and parathyroid surgery. Surg Endosc doi: 10.1007/ s00464-017-5424-1.

12. McWade MA, Paras C, White LM, Phay JE, Mahadevan-Jansen A, et al. (2013) A novel optical approach to intraoperative detection of parathyroid glands. Surgery 154(6): 1371-1377.

13. McWade MA, Sanders ME, Broome JT, Solórzano CC, MahadevanJansen A (2016) Establishing the clinical utility of Autofluorescence spectroscopy for parathyroid detection. Surgery159(1): 193-202.

14. Shinden Y, Nakajo A, Arima H, Tanoue K, Hirata M, et al. (2017) Intraoperative identification of the parathyroid gland with a fluorescence detection system. World J Surg 41(6): 1506-1512.

15. Hou F, Yu Y, Liang Y (2017) Automatic identification of parathyroid in optical coherence tomography images. Lasers Surg Med 49(3): 305311.

16. Hyun H, Park MH, Owens EA, Wada H, Henary M, et al. (2015) Structureinherent targeting of NIR fluorophores for parathyroid and thyroid gland imaging. Nature med 21(2): 192-197.

17. Suh YJ, Choi JY, Chai YJ, Kwon H, Woo JW, et al. (2015) Indocyanine green as a near-infrared fluorescent agent for identifying parathyroid glands during thyroid surgery in dogs. Surg Endosc 29(9): 2811-2817.

18. Lavazza M, Liu X, Wu C, Anuwong A, Kim HY, et al. (2016) Indocyanine green-enhanced fluorescence for assessing parathyroid perfusion during thyroidectomy. Gland Surg 5(5): 512-521.

19. Bian XH, Li SJ, Zhou L, Zhang CH, Zhang G, et al. (2016) Applicability of rapid intraoperative parathyroid hormone assay through fine needle aspiration to identify parathyroid tissue in thyroid surgery. Exp Ther Med 12(6): 4072-4076.
Your next submission with Juniper Publishers will reach you the below assets

- Quality Editorial service

- Swift Peer Review

- Reprints availability

- E-prints Service

- Manuscript Podcast for convenient understanding

- Global attainment for your research

- Manuscript accessibility in different formats

( Pdf, E-pub, Full Text, Audio)

- Unceasing customer service

Track the below URL for one-step submission https://juniperpublishers.com/online-submission.php 